\title{
Heparin Binding Growth Factor
}

National Cancer Institute

\section{Source}

National Cancer Institute. Heparin Binding Growth Factor. NCI Thesaurus. Code C41029.

Mitogenic factors with high affinity for heparin. These proteins regulate the proliferation and differentiation of mesenchymal, epithelial, and neuroectodermal cells. Heparinbinding may sequester these proteins in the extracellular matrix, or increase the stability of these growth factors. Heparin may enhance the activity of some family members, as it may be required for their interactions with cellular receptors. 